\title{
Efeito cicatrizante e atividade antibacteriana da Calendula officinalis $L$. cultivada no Brasil
}

\author{
PARENTE, L.M.L. ${ }^{* *}$; SILVA, M.S.B. ${ }^{1}$; BRITO, L.A.B. ${ }^{1}$; LINO-JÚNIOR, R.S. ${ }^{2}$; PAULA, J.R. ${ }^{3}$; TREVENZOL, L.M.F. ${ }^{3}$; \\ ZATTA, D.T. ${ }^{3}$; PAULO, N.M. ${ }^{1}$ \\ ${ }^{1}$ Departamento de Medicina Veterinária, Escola de Veterinária,Universidade Federal de Goiás - UFG. Campus \\ Samambaia (Campus II). Caixa Postal 131 - CEP: 74001-970 - Goiânia-Brasil *lathosvet@hotmail.com. ${ }^{2}$ Setor de \\ Patologia Geral, Instituto de Patologia Tropical e Saúde Pública- ${ }^{3}$ Laboratório de Pesquisa em Produtos Naturais \\ Faculdade de Farmácia-UFG. CEP: 74001-970 - Goiânia-Brasil
}

\begin{abstract}
RESUMO: Desde a antiguidade propriedades medicinais são atribuídas às flores da Calendula officinalis L. (Asteraceae) destacando-se a atividade cicatrizante. Estudos sobre a atividade geral de plantas medicinais na cicatrização vêm sendo realizados, sem especificar sobre qual das fases da cicatrização a planta atua. Neste trabalho a atividade cicatrizante e antiinflamatória do extrato etanólico das flores da $C$. officinalis cultivada no Brasil foi avaliada em feridas cutâneas de ratos Wistar, por meio de avaliação macroscópica e histológica. A atividade antimicrobiana do extrato e das frações hexânica e diclorometano também foi avaliada. A atividade antiinflamatória do extrato etanólico da calêndula foi atribuída à diminuição da exsudação serosa, da hiperemia, da deposição de fibrina e da hiperplasia epidermal, além de resultar em crostas mais delgadas e umedecidas. Observaram-se também aumento de colágeno no tecido de granulação e efeito antibacteriano. Assim, o extrato etanólico da calêndula atuou de forma positiva sobre a atividade cicatricial em feridas cutâneas de ratos, bem como apresentou atividade antibacteriana in vitro.
\end{abstract}

Palavras-chave: reparo, calêndula, fases da cicatrização, plantas medicinais

\begin{abstract}
Healing effect and antibacterial activity of Calendula officinalis L. cultivated in Brazil. Since ancient history medicinal properties are attributed to flowers of Calendula officinalis L. (Asteraceae), mainly concerning its healing activity. Studies about the general activity of medicinal plants in healing wounds have been conducted without specifying in which healing phase the plant acts. In this work, the anti-inflammatory and healing activity of the ethanolic extract of $C$. officinalis flowers cultured in Brazil was evaluated in cutaneous wounds of Wistar rats through macroscopic and histological evaluation. The antibacterial activity of the extract and dichloromethane and hexane fractions was also evaluated. The anti-inflammatory activity of calendula ethanolic extract led to a reduction in plasmatic exudation, hyperemia, fibrin deposition and epidermal hyperplasia, besides resulting in less edematous crusts. There was also an increase in collagen in the granulation tissue and an antibacterial effect. Therefore, calendula ethanolic extract positively acted on the healing process of cutaneous wounds of rats and presented in vitro antibacterial activity.
\end{abstract}

Key words: repair, pot marigold, healing phases, medicinal plants

\section{INTRODUÇÃO}

O processo de cicatrização dérmica iniciase logo após a lesão, ocorrendo formação do coágulo sanguíneo que atua como tampão hemostático e substrato para a organização da ferida e estabelecimento do tecido de granulação (Midwood et al., 2004; Hosgood, 2006).

Durante séculos tem-se buscado nas plantas medicinais alternativas para o tratamento de diversas doenças dermatológicas (Raskin et al., 2002), principalmente naquelas que apresentam

Recebido para publicação em 02/09/2008

Aceito para publicação em 06/04/2009

Rev. Bras. PI. Med., Botucatu, v.11, n.4, p.383-391, 2009. 
processos cicatriciais de difícil resolução. (Hsu, 2005). Na Antigüidade de forma empírica já eram conhecidas algumas propriedades medicinais atribuídas às flores da Calendula officinalis $L$ (C.officinalis), popularmente conhecida como calêndula. É uma planta herbácea anual, originaria da região Mediterrânea, pertencente à família Asteraceae (Alonso, 1998).

A calêndula tem sido usada rotineiramente em aplicações tópicas, tanto em cosmetologia como em dermatologia (Della-Loggia et al., 1994; ZitterlEglseer et al., 1997; Hamburguer et al., 2003). Entre as suas atribuições terapêuticas mais difundidas estão a reepitelização e cicatrização de feridas (Alonso, 1998), sendo ainda utilizadas em equimoses, erupções e em outras lesões da pele. A medicina popular européia recomenda seu uso no tratamento de eczemas (Brown \& Dattner, 1998).

Os resultados de pesquisas da atuação farmacológica das plantas medicinais na cicatrização envolvendo animais e humanos, na sua maioria não especificam sobre quais das fases desse processo a atividade foi evidenciada (Krishnan, 2007). Com base nos relatos da literatura e no sentido de investigar em qual das fases da cicatrização a calêndula age, a proposta do presente trabalho fundamentou-se em avaliar o efeito do extrato etanólico das flores da $C$. officinalis cultivadas no Brasil na cicatrização de feridas cutâneas em ratos. Avaliou-se também a atividade antibacteriana do extrato etanólico e das frações hexânica e diclorometano.

\section{MATERIAL E MÉTODO}

\section{Obtenção do extrato etanólico (EEC) e das frações diclorometano (FDC) e hexânica (FHC) \\ Utilizaram-se flores secas e pulverizadas da} C.officinalis L, pertencente à família Asteraceae, denominada popularmente de calêndula, originadas do Estado do Paraná (fevereiro, 2002) e obtidas da Empresa Clorophila, sediada em Goiânia, GO (Laudo de Análise no 6733/02). Para o controle de qualidade da calêndula foi realizada a avaliação farmacognóstica no Laboratório de Pesquisa em Produtos Naturais da Faculdade de Farmácia da Universidade Federal de Goiás (UFG). Os dados obtidos estão de acordo com técnicas descritas na Farmacopéia Brasileira IV (2001) e nas Monografias da Organização Mundial de SaúdeWHO (2002) para essa espécie vegetal.

Para a preparação do extrato etanólico (EEC), $200 \mathrm{~g}$ das flores pulverizadas foram extraídos com $1000 \mathrm{~mL}$ de etanol PA 96 GL, por maceração, durante três dias, à temperatura ambiente, com agitação ocasional e concentrado em evaporador rotativo a $40^{\circ} \mathrm{C}$ (Ferri, 1996).

Para a obtenção das frações hexânica e diclorometano, $10 \mathrm{~g}$ do EEC foi solubilizado em uma mistura metanol/ $\mathrm{H}_{2} \mathrm{O}(7: 1)$ e extraída por três vezes com $50 \mathrm{~mL}$ de hexano e, posteriormente, extraída por três vezes com $50 \mathrm{~mL}$ de diclorometano. Os extratos foram concentrados em evaporador rotativo (Ferri, 1996). Uma solução aquosa do extrato etanólico a $1 \%$ foi preparada diariamente para avaliação da atividade cicatrizante. $O$ extrato etanólico e as frações concentradas foram solubilizados em DMSO para a verificação da atividade antimicrobiana.

\section{Atividade cicatrizante em feridas cutâneas}

Foram utilizados 36 ratos (Rattus norvegicus albinus), da linhagem Wistar, fêmeas, com 60 dias de idade, peso entre 160 a $190 \mathrm{~g}$, provenientes do entre 50 a 60 dias de idade, pesando entre 160 e 190 gramas no início do experimento, provenientes do Biotério Central da UFG. O trabalho foi aprovado pelo Comitê de Ética em Pesquisa da Universidade Federal de Goiás, sob o protocolo № 019/2007.

Os animais foram adaptados no Biotério de Cirurgia Experimental da Escola de Veterinária da UFG, por um período de dez dias e mantidos em gaiolas individuais de polietileno, forradas com maravalha, sob condições ambientais controladas (temperatura $23 \pm 2^{\circ} \mathrm{C}$, umidade relativa do ar entre 50 e $70 \%$ e fotoperíodo claro/escuro de 12h). Água e ração foram fornecidos ad libitum.

Os animais foram pesados e divididos de forma aleatória, em dois grupos com 18 ratas e subdivididos em três subgrupos $(n=6)$, para serem estudados de acordo com o seguinte protocolo de avaliação pós-operatória (PO):

Grupo 1 - Controle (C), animais tratados com água destilada, sendo C1 (dia 4 PO), C2 (7o dia PO) e C3 (14ㅇdia PO).

Grupo 2 - EEC, animais tratados com solução aquosa do extrato etanólico a 1\%, sendo EEC1 (4은 dia PO), EEC2 (7ㅇdia PO) e EEC3 (14ㅇdia PO).

Para a indução da ferida utilizou-se um punch metálico circular de $1 \mathrm{~cm}$ de diâmetro na região dorsocervical de cada animal. A anestesia consistiu da administração, por via muscular, da associação de cloridrato de cetamina e cloridrato de xilazina nas doses de $70 \mathrm{mg} \mathrm{Kg}^{-1}$ e $10 \mathrm{mg} \mathrm{Kg}^{-1}$, respectivamente (Pachaly, 2006).

Logo após a cirurgia e diariamente no mesmo horário, $100 \mu \mathrm{L}$ da solução teste (EEC) e do solvente foram instiladas nas feridas dos animais.

Todos os animais foram examinados diariamente quanto ao aspecto geral, ocasião em que se procedia a avaliação macroscópica da ferida, observando-se a presença ou ausência de hemorragia, exsudato e crosta, sendo os dados registrados em fichas individuais. Os animais foram pesados e sacrificados em câmara de $\mathrm{CO}_{2}$ aos 4,7 e 14 dias do $\mathrm{PO}$, conforme protocolos preconizados por Lopes et 
al. (2005) e Garros et al. (2006).

Para a análise morfométrica, as feridas foram fotografadas nos dias zero, 4,7 e 14 do PO, utilizando-se de uma câmera digital acoplada em tripé, mantida a uma distância constante de $27 \mathrm{~cm}$ da ferida, e em seguida, as imagens foram digitalizadas em microcomputador, com o auxílio do Software Image $J$ 1.3.1 ( $\mathrm{NIH}$, Estados Unidos). O grau de contração da área (GC) da ferida foi calculado por meio da fórmula demonstrada por Oliveira et al. (2000):

$$
\begin{aligned}
\mathrm{GC}= & \frac{\text { Área } \mathrm{T}^{\circ}-\text { Área } \mathrm{T}^{\text {dia sacriticio }} \times 100}{\text { Área } \mathrm{T}^{\circ}} \\
& \begin{array}{c}
\text { Onde: } \mathrm{T}^{\mathrm{O}}=\text { dia zero } \\
\mathrm{T}^{\text {dia sacrificio }}=\operatorname{dias} 4,7 \text { ou } 14 \mathrm{PO} .
\end{array}
\end{aligned}
$$

Para a avaliação histológica, um fragmento de cada ferida foi retirado, fixado em formol tamponado a $10 \%$, processado e corado com Hematoxilina e Eosina (HE), de acordo com Luna (1968). Utilizou-se também a coloração especial de Picrossírius para a quantificação do colágeno, sob luz polarizada (López de Leon \& Rojkind, 1985), calculando-se a porcentagem de área marcada em verde ou amarelo-avermelhada por campo, por meio do software Image J 1.3.1 (NIH, Estados Unidos).

Ao exame histológico, nos dias 4, 7 e 14 $\mathrm{PO}$, foram avaliadas as variáveis fibrina, hemorragia, hiperemia, infiltrado inflamatório, reepitelização e hiperplasia epitelial. Adotaram-se escores adaptados de Biondo-Simões et al. (2006), onde:

- Para fibrina, hemorragia, hiperemia e infiltrado inflamatório utilizaram-se os escores ausente (0), discreto (1 a $25 \%$ ), moderado (25 a $50 \%$ ) e acentuado (acima de 50\%), avaliados aos 4 e 7 ㅇ dias PO. Para a hiperplasia epidermal utilizaram-se os mesmos escores, avaliada no dia $14 \mathrm{PO}$;

- Para a reepitelização utilizaram-se os escores total ou parcial, avaliada no 14일 PO;

\section{Atividade antibacteriana in vitro}

A avaliação da atividade antibacteriana foi realizada utilizando cepas padrão American Type Culture Collection (ATCC) e isolados pertencentes a bacterioteca do Laboratório de Bacteriologia Médica do Instituto de Patologia Tropical e Saúde Pública da UFG. Para determinar a Concentração Inibitória Mínima (CIM), foram utilizadas culturas de Staphylococcus aureus (ATCC 6532), Staphylococcus aureus (ATCC 13048), Micrococcus roseus (ATCC 1740), Micrococcus luteus (ATCC 9341), Bacillus cereus (ATCC 14576), Bacillus stearothermophylus (ATCC 1262), Enterobacter cloacae (HMA/FTA 502), Enterobacter aerogenes (ATCC 13048), Escherichia coli (ATCC 25922), Pseudomonas aeruginosa (ATCC 9027) e Serratia marcescens (ATCC 14756) e método de diluição em placa.
Os microrganismos foram reativados em caldo tioglicolato (Difco), incubados a $37^{\circ} \mathrm{C}$, por 24 48 horas e, em seguida, repicados em ágar simples inclinado (Difco). Para preparação do inóculo das bactérias a serem utilizados no aplicador de Steers, as bactérias foram suspensas em solução salina estéril e a turvação comparada com padrão 0,5 da Escala 1da Mac Farland (NCCLS, 2003).

Para avaliação da concentração inibitória mínima (CIM) pelo método de diluição em placa, 1000 $\mathrm{mg}$ do extrato etanólico bruto das flores de calêndula, $500 \mathrm{mg}$ da fração hexânica e $350 \mathrm{mg}$ da fração diclorometano foram colocados em tubos de ensaio contendo $1,0 \mathrm{~mL}$ de DMSO. Após solubilização adicionou-se $1,0 \mathrm{~mL}$ de solução salina e realizou-se uma diluição seriada 1:2 para cada amostra. A cada tubo adicionou-se $19 \mathrm{~mL}$ de ágar Mueller Hinton, de modo a se obter placas com concentrações de $50 \mathrm{a}$ $0,39 \mathrm{mg} \mathrm{mL}^{-1}$ do extrato bruto, 25 a $0,195 \mathrm{mg} \mathrm{mL}^{-1} \mathrm{da}$ fração hexânica e 17,5 a $0,125 \mathrm{mg} \mathrm{mL}^{-1}$ da fração diclorometano. Para controle do solvente, uma placa contendo $1 \mathrm{~mL}$ de DMSO foi preparada nas mesmas condições. Os inóculos microbianos foram aplicados nas placas com o auxílio do inoculador de Steers (Steers et al., 1959). As placas foram incubadas a $37^{\circ} \mathrm{C}$ por 24 horas para as bactérias. Foi considerada CIM a menor concentração dos extratos que inibiu o crescimento das bactérias.

\section{Análise estatística}

Os resultados foram submetidos a tratamento estatístico utilizando-se do programa GraphPad InStat (Version 3.05 for Windows). Para análise das variáveis paramétricas foi utilizado o teste t não-pareado e o teste de Mann Whitney para as não-paramétricas. $O$ nível de significância foi de $p<0,05$ (Sampaio, 1998).

\section{RESULTADO E DISCUSSÃO}

\section{Atividade cicatrizante em feridas cutâneas}

O procedimento operatório e o tratamento pós-operatório transcorreram sem complicações. Todos os animais recuperaram-se bem da anestesia, demonstrando bom estado geral e atividades física e comportamental normais para a espécie. Não foi observado exsudato purulento em nenhuma das feridas cutâneas, mas constatou-se exsudação serosa nos animais do grupo EEC até o $4^{\circ}$ dia, e no grupo controle até o 7ㅇ dia PO.

As crostas começaram a se formar no dia 3 , sendo que no grupo EEC apresentaram-se mais delgadas e umedecidas em relação ao grupo controle, que se demonstraram espessas e ressecadas. No 70 dia PO, nos dois grupos, as crostas começaram a se destacar, havendo sinais de epitelização da ferida. 
No 14 dia PO foi verificada cicatrização completa das feridas em ambos os grupos.

Martins et al. (2003), ao tratarem feridas cutâneas em cavalos com uma solução hidroalcóolica de $C$. officinalis cultivada no Brasil, observaram que na fase inflamatória as crostas apresentavam-se serosas e lisas, com bordos mais delgados em relação ao controle, o que também foi verificado nas feridas cutâneas dos ratos tratados com EEC deste estudo. Apesar de a resposta cicatricial ser naturalmente diferente nas espécies estudadas, reitera-se o efeito antiinflamatório verificado nas feridas cutâneas de cavalos e ratos tratados com extratos da calêndula. Não fosse isso, possivelmente, as feridas cutâneas dos eqüinos não teriam apresentado reação cicatricial mais discreta naqueles animais tratados com uma solução hidroalcóolica de calêndula, já que preparações tópicas freqüentemente são irritantes e estimulam tecido de granulação exuberante nesta espécie (White, 1995).

A área da ferida cutânea dos ratos diminuiu gradativamente com a evolução do processo de cicatrização nos dois grupos e não houve diferença significativa (Tabela 1), contudo, a observação macroscópica diária e os valores médios obtidos nas mensurações de contração de ferida permitiram concluir que a retração centrípeta foi beneficiada, especialmente aos 40 e 7을 Resultado semelhante também foi obtido por Martins et al. (2003), quando mensuraram área de feridas cutâneas de eqüinos tratadas com solução hidroalcóolica de calêndula.

Observou-se que as variáveis fibrina e hiperemia nos dias 4 e 7 PO apresentaram diferença significativa quando comparadas com o controle (Tabelas 2 e 3, Figuras 2 e 3).
TABELA 1. Valores médios e desvio padrão da contração das feridas cutâneas em ratos (\%) dos grupos controle e EEC aos 4 e 7ㅇ dias PO.

\begin{tabular}{ccc}
\hline & \multicolumn{2}{c}{ Dias PO } \\
\cline { 2 - 3 } Grupos & $4^{\underline{0}}$ & $7^{0}$ \\
\hline Controle & $36,60 \pm 7,73^{\text {a }}$ & $42,24 \pm 9,12^{\text {a }}$ \\
EEC & $43,51 \pm 9,97^{\mathrm{a}}$ & $47,91 \pm 19,26^{\mathrm{a}}$ \\
\hline
\end{tabular}

Letras iguais não diferem entre si. Teste $t$ não-pareado $(p<0,05)$

A atividade antiinflamatória da calêndula foi anteriormente evidenciada em camundongos por DellaLogglia et al. (1990), Della-Loggia et al. (1994), ZitterlEglseer et al. (1997), Alonso (1998), WHO (2002) e Hamburguer et al. (2003), utilizando modelos de indução de edema de orelha por óleo de cróton e de edema de pata por carragenina. Esses testes avaliam substâncias que apresentam atividade sobre os produtos da ciclooxigenase (COX), principalmente as prostaglandinas, pelo fato do óleo de cróton e da carragenina produzirem edema mediado por esses compostos (Lapa et al., 2003). Assim, supõe-se que a atividade antiinflamatória da $C$. officinalis esteja relacionada a sua atividade sobre os derivados da COX.

No presente trabalho a metodologia envolveu feridas cutâneas de ratos tratadas com o extrato etanólico de $C$. officinalis cultivada no Brasil. Apesar das diferenças quanto ao modelo experimental e origem da planta entre os estudos, a atividade antiinflamatória da calêndula também foi constatada, já que houve diferença significativa quanto às variáveis fibrina e hiperemia, que compreendem alterações circulatórias diretamente relacionadas à inflamação.

No 14을 dia PO observou-se reepitelização total da ferida nos dois grupos e diferença significativa

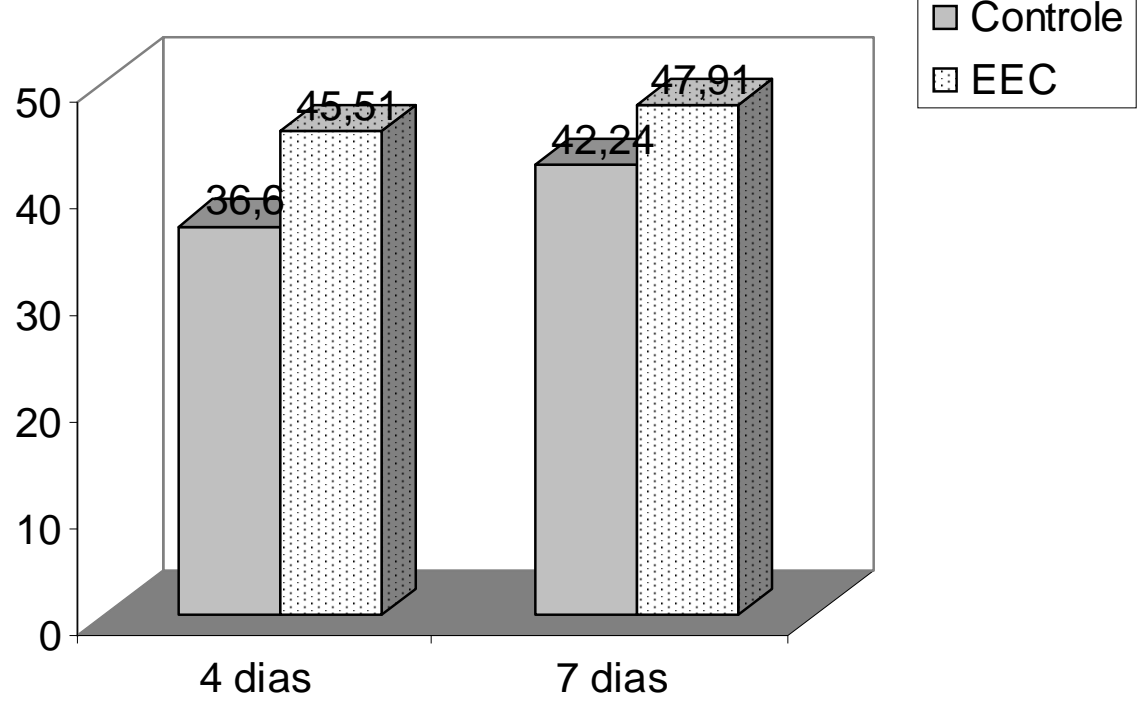

FIGURA 1. Médias da contração das feridas cutâneas em ratos (\%) nos dias 4 e 7 PO. 
TABELA3. Medianas das variáveis histológicas avaliadas ao 7ํ dia PO dos grupos controle e EEC.

\begin{tabular}{lccc}
\hline Variáveis histológicas & Controle & EEC & $\mathrm{P}$ \\
\hline Fibrina & $3,0^{\mathrm{a}}$ & $2,0^{\mathrm{b}}$ & 0,041 \\
Hiperemia & $2,5^{\mathrm{a}}$ & $1,5^{\mathrm{b}}$ & 0,026 \\
Hemorragia & $3,0^{\mathrm{a}}$ & $3,0^{\mathrm{a}}$ & 0,999 \\
Infiltrado inflamatório (PMN) & $3,0^{\mathrm{a}}$ & $3,0^{\mathrm{a}}$ & 0,937 \\
& & &
\end{tabular}

$P=$ nível de significância. Letras iguais não diferem entre si (Teste de Mann-Whitney, $p<0,05)$.
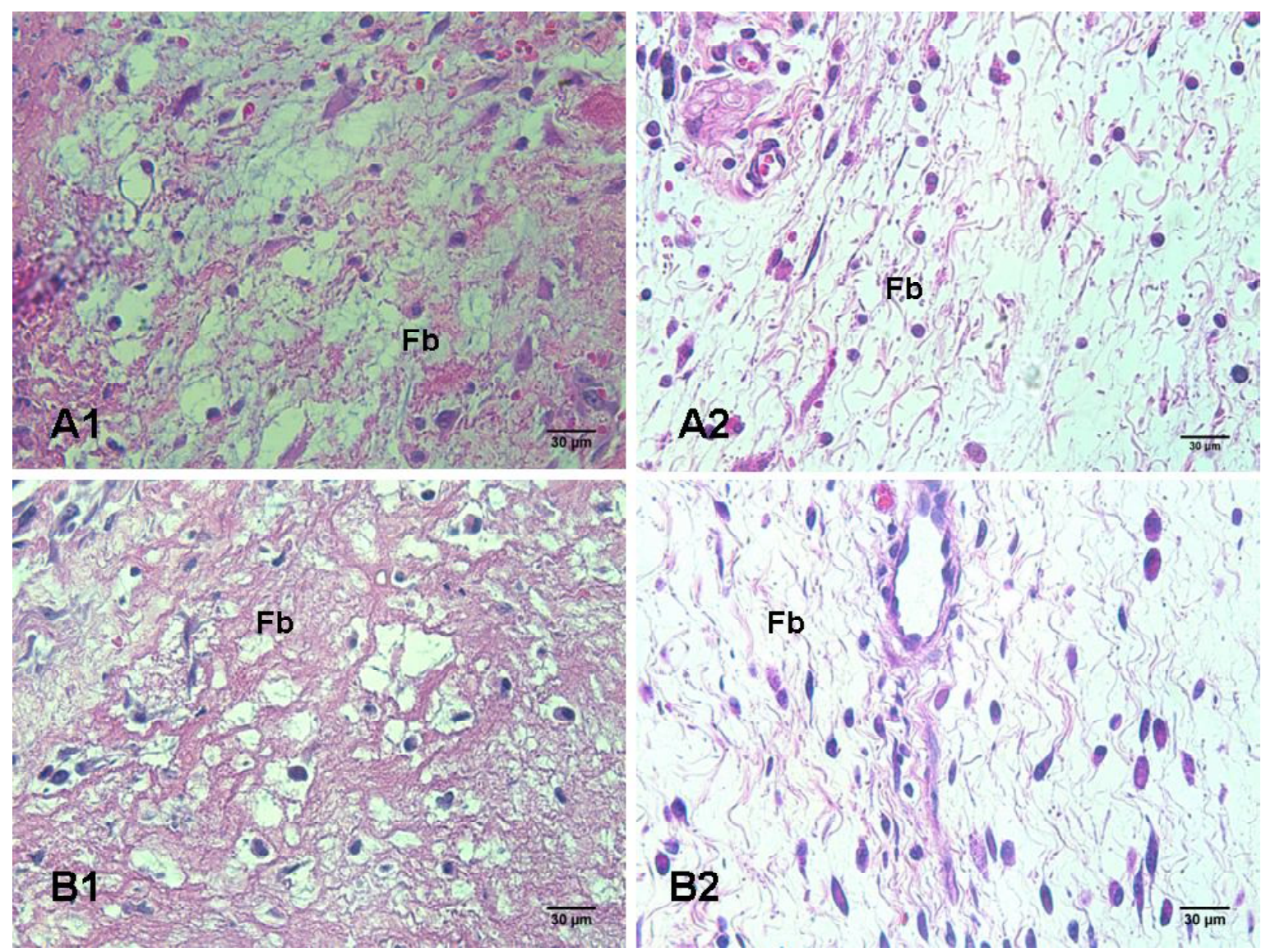

FIGURA2. Fotomicrografias das feridas cutâneas em ratos aos 4 (A) e 7 (B) dias PO, evidenciando fibrina (Fb). A1 e B1 referem-se ao controle e A2 e B2 ao EEC, respectivamente. Hematoxilina-eosina.

quanto à hiperplasia epidermal (Tabela 4 e Figura 4). A hiperplasia corresponde ao aumento no número de células em conseqüência do aumento no ritmo de divisão celular com manutenção do padrão morfofuncional (Montenegro \& Franco, 1999). No caso de hiperplasias que ocorrem junto ao processo inflamatório, estas têm sua gênese a partir de fenômenos intrínsecos da inflamação, como a hiperemia e a síntese de substâncias que estimulam a divisão celular. Dessa forma, quanto maior e mais duradoura for a resposta inflamatória, maior será a reação hiperplásica das células envolvidas no processo (Faria et al., 2003).

Nesse âmbito, a menor reação hiperplásica epidermal, verificada nas feridas cutâneas de ratos tratados com EEC e constatada estatisticamente, possivelmente relaciona-se à atividade antiinflamatória da calêndula, já que as feridas cutâneas de ratos tratadas com EEC apresentaram resposta inflamatória reduzida quando comparada ao grupo controle e evidenciada pela menor hiperemia e deposição de fibrina junto à reação inflamatória. 


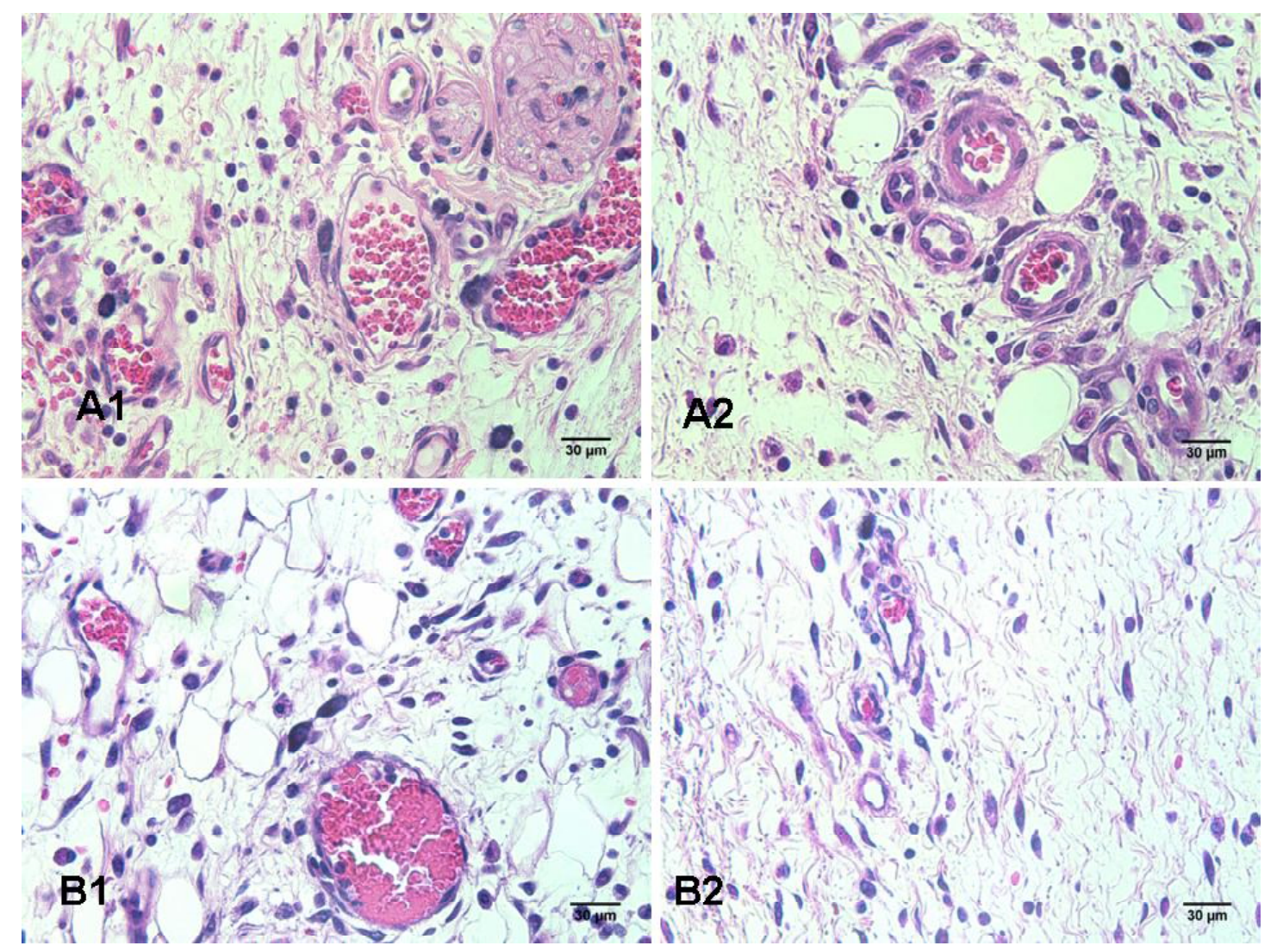

FIGURA 3. Fotomicrografia da ferida cutânea em ratos aos 4 (A) e 7 (B) dias PO, evidenciando hiperemia. Grupos controle (A1 e B1) e EEC (A2 e B2), respectivamente. Hematoxilina-eosina.
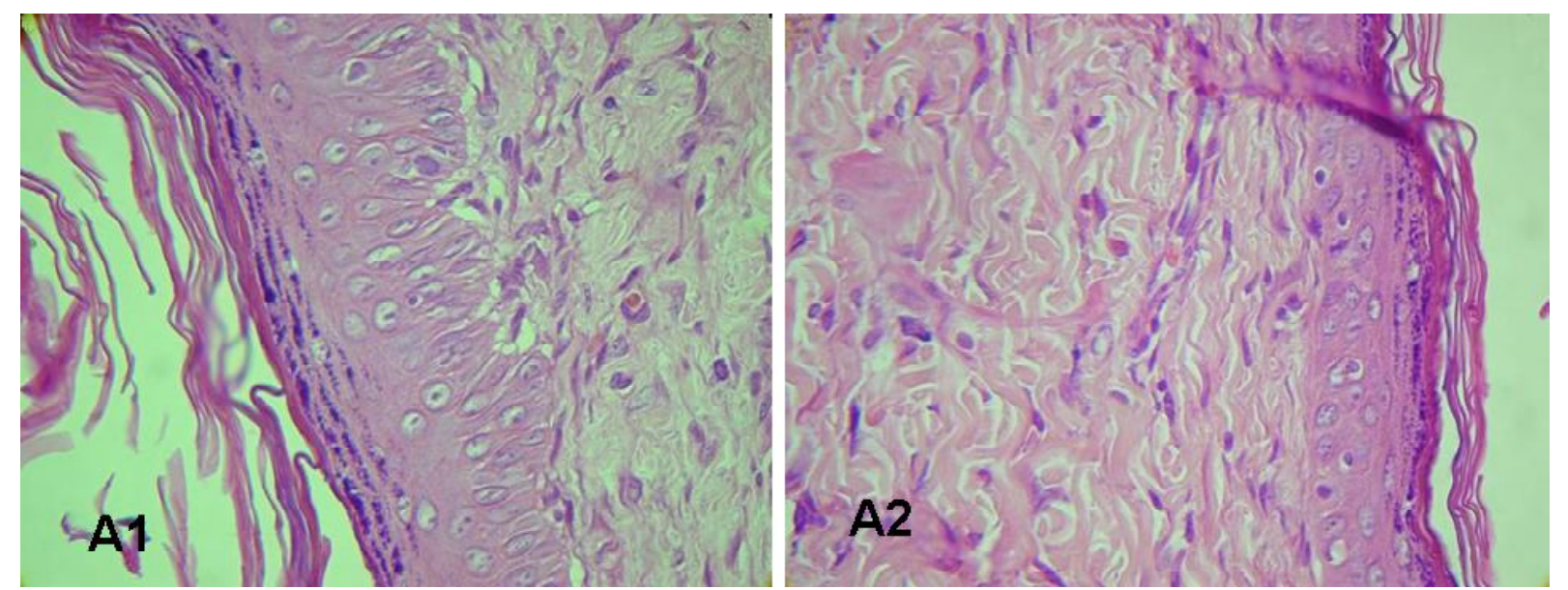

FIGURA 4. Fotomicrografia da ferida cutânea de ratos evidenciando a hiperplasia epidermal. Grupos controle (A1) e EEC (A2) no 14 dia PO. Hematoxilina-eosina. 100x

À morfometria, houve diferença significativa quanto à quantidade de colágeno entre os grupos controle e EEC nos dia 4 e 7 PO (Tabelas 5 e Figura 5). No 4o dia PO foi evidenciada coloração verde brilhante do colágeno nos dois grupos e no $7^{\circ}$ dia PO coloração amarelo-avermelhada, principalmente no grupo EEC.

Observou-se que, no decorrer do processo de reparo da ferida, o colágeno tipo III foi gradativamente
TABELA4. Medianas da variável hiperplasia epidermal avaliada no 14 dia PO dos grupos controle e EEC.

\begin{tabular}{lccc}
\hline Variável histológica & Controle & EEC & $\mathrm{P}$ \\
\hline Hiperplasia epitelial & $3,0^{\mathrm{a}}$ & $1,0^{\mathrm{b}}$ & 0,046
\end{tabular}

$\mathrm{P}=$ nível de significância. Letras diferentes diferem entre si (Teste de Mann-Whitney, $\mathrm{p}<0,05)$. 
substituído pelo colágeno tipo I, sendo esse efeito evidenciado pela mudança de coloração do colágeno de verde para amarelo-avermelhado. Borges et al. (2007) descrevem que o colágeno é o principal constituinte do tecido conectivo e pode ser bem evidenciado pela coloração Picrossírius. Nesse método, as fibras colágenas mais delgadas e menos organizadas, que correspondem ao colágeno tipo III, apresentam coloração verde brilhante devido a menor birrefringência. O colágeno tipo I, que é mais organizado e possui maior birrefringência, apresenta coloração amarelada ou avermelhada. Não foram encontradas referências na literatura sobre mensuração de colágeno pelo Picrossírius em feridas cutâneas tratadas com $C$. officinalis. Neste trabalho, a confirmação estatística do aumento da concentração de colágeno nas feridas tratadas com EEC aos $4^{\circ} \mathrm{e}$ 70 dias PO (Tabelas 5 e 6), indica que o EEC estimulou maior síntese colágena, atuando assim, de forma positiva no processo da cicatrização das feridas cutâneas.

\section{Atividade antibacteriana in vitro}

O EEC e a fração hexânica apresentaram maior atividade antibacteriana, mostrando-se mais efetivos frente a bactérias Gram-positivas do que a
TABELA 5. Medianas da variável colágeno, avaliada por morfometria, nos 40 e 70 dias PO dos grupos controle e EEC.

\begin{tabular}{cccc}
\hline $\begin{array}{c}\text { Tempo de } \\
\text { avaliação (PO) }\end{array}$ & Controle & EEC & $\mathrm{P}$ \\
\hline $4^{\circ}$ dia & $5,33^{\mathrm{a}}$ & $8,27^{\mathrm{b}}$ & 0,025 \\
$7^{\circ}$ dia & $4,31^{\mathrm{a}}$ & $6,23^{\mathrm{b}}$ & 0,015
\end{tabular}

$\mathrm{P}=\overline{\text { nível de significância. Letras diferentes diferem significativamente }}$ (Teste de Mann-Whitney, $p<0,05$ ).

fração diclorometano. As menores concentrações dos extratos que inibiram o crescimento dos microrganismos testados foram EEC, CIM de $0,39 \mathrm{mg} \mathrm{mL}^{-1}$, frente $a$ S. aureus 13048 e B. stearo thermophylus; FDC, CIM de $4,37 \mathrm{mg} / \mathrm{mL}$, frente a S.aureus 6532 e S.aureus 13048, CIM de $1,08 \mathrm{mg} \mathrm{mL}^{-1}$, frente a $B$. stearo thermophylus e $B$. cereus, CIM de $0,5 \mathrm{mg} \mathrm{mL}^{-1}$, frente a M. roseus; e FHC, CIM de $0,19 \mathrm{mg} \mathrm{mL}^{-1}$, frente a $S$. aureus 13048.

Feridas abertas estão propensas a contaminações por bactérias, podendo representar uma porta de entrada para infecções sistêmicas. Quando ocorre contaminação, há formação de uma grande quantidade de exsudato e produção de
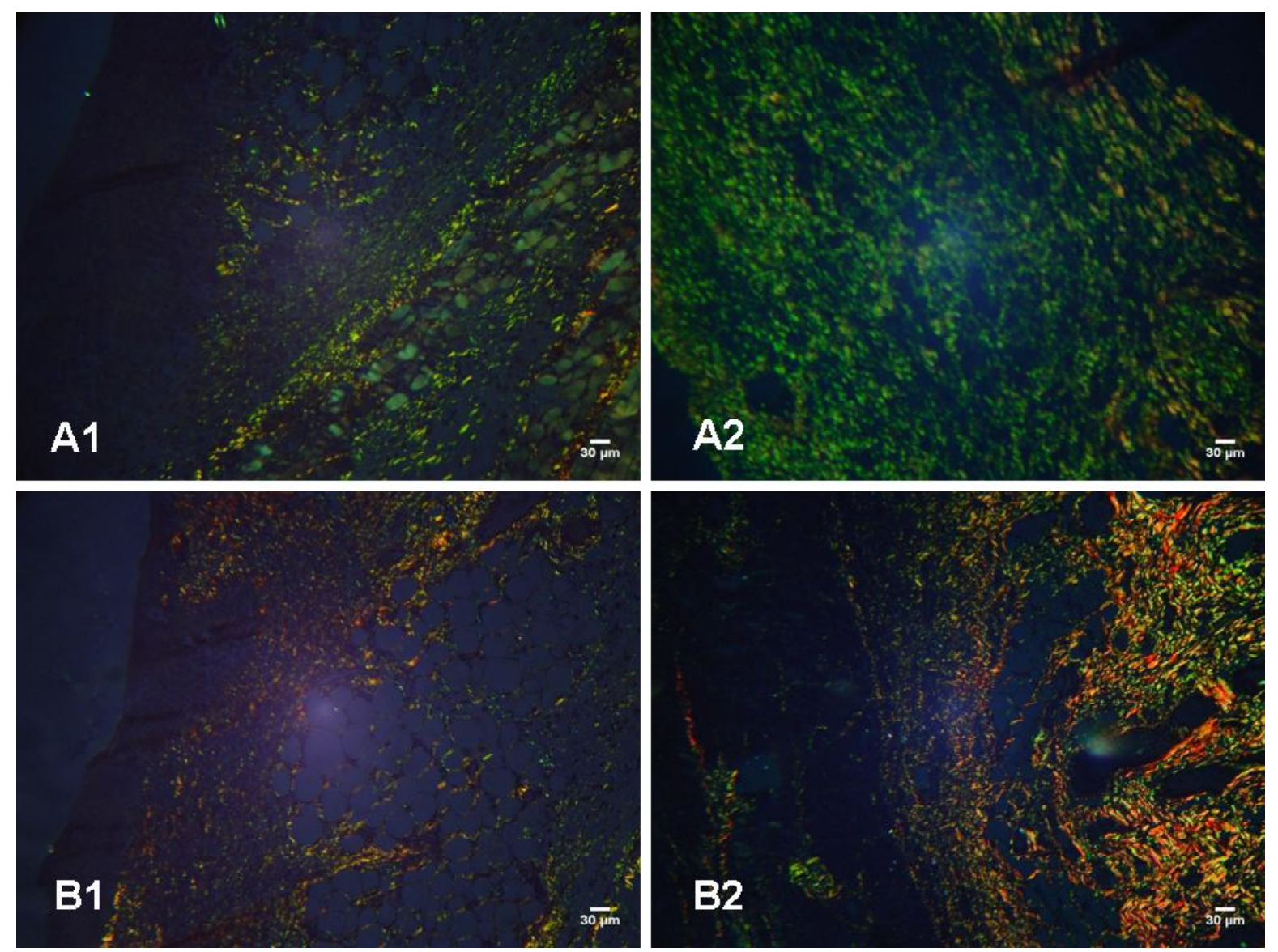

FIGURA 5. Fotomicrografia da ferida cutânea em ratos aos $4(\mathrm{~A})$ e 7 (B) dias PO, evidenciando colágeno. Grupos controle (A1 e B1) e EEC (A2 e B2), respectivamente. Picrossírius. 100x 
toxinas, retardando o reparo da ferida (Houghton et al., 2005).

Dados da CIM indicaram que o extrato etanólico e as frações diclorometano e hexânica da calêndula apresentaram atividade antibacteriana, principalmente sobre bactérias gram-positivas. Resultado semelhante foi observado por Volpato (2005) ao avaliar a atividade antimicrobiana do extrato etanólico e das frações hexânica e diclorometano de C.officinalis do Brasil, utilizando a metodologia da cavidade em placa e extração em aparelho de Soxhlet. Apesar das diferenças metodológicas, os resultados obtidos em ambos os experimentos reiteram a atividade antibacteriana da calêndula.

Conclui-se que as flores da $C$. officinalis cultivada no Brasil apresentam efeitos positivos sobre a atividade cicatricial em feridas cutâneas de ratos, bem como sobre a atividade antibacteriana in vitro.

\section{AGRADECIMENTO}

Este trabalho foi realizado com a colaboração dos Setores de Patologia Animal e Medicina Veterinária Preventiva da Escola de Veterinária, do Laboratório de Pesquisa em Produtos Naturais da Faculdade de Farmácia e do Setor de Patologia Geral do Instituto de Patologia Tropical e Saúde Pública todos da Universidade Federal de Goiás.

\section{REFERÊNCIA}

ALONSO, J.R. Tratado de fitomedicina: bases clínicas y farmacológicas. Buenos Aires: Isis, 1998. 1038p.

BIONDO-SIMÕES, M.L.P. et al. Cicatrização de feridas: estudos comparativo em ratos hipertensos não tratados e tratados com inibidor da enzima conversora da angiotensina. Revista do Colégio Brasileiro de Cirurgiões, v.33, n.2, p.74-8, 2006.

BORGES, L.F. et al. Picrossírius-polarization staining method as an efficient histopathological tool for collagenolysis detection in vesical prolapse lesions. Mícron, v.38, p.580-3, 2007.

BROWN, D.J.; DATTNER, A.M. Phytotherapeutic Approaches to Common Dermatologic Conditions. Achta Dermatological, v.134, p.1401-4, 1998.

DELLA-LOGGIA, R. et al. Topical anti-inflammatory activity of Calendula officinalis extracts. Planta Médica, v.56, p.658, 1990.

DELLA-LOGGIA, R. et al. The Role of Triterpenoids in the Topical Anti-inflammatory Activity of Calendula officinalis Flowers. Planta Medica, v.60, p.516-20, 1994.

FARIA, J.L. et al. Patologia geral: fundamentos das doenças com aplicações clínicas. 4.ed. Rio de Janeiro: Guanabara Koogan, 2003. 360p.

FARMACOPÉIABRASILEIRA IV. São Paulo:Ateneu, 2001. 420p.

FERRI, P.H. Química dos produtos naturais: métodos gerais. In: DI SATSI, L.C. (Ed.) Plantas medicinais: arte e ciência, um guia de estudos interdisciplinares. São
Paulo: Editora da UEP, 1996. p.132-40.

GARROS, I.C. et al. Extrato de Passiflora edulis na cicatrização de feridas cutâneas abertas em ratos: estudo morfológico e histológico. Acta Cirúrgica Brasileira, v.21, supl. 3, p.55-65, 2006.

HAMBURGUER, M. et al. Preparative purification of the major anti-inflammatory triterpenoid ester from Marigold (Calendula officinalis). Fitoterapia, v.74, p.328-38, 2003. HOSGOOD, G. Stages of wound healing and their clinical relevance. Veterinary Clinics, Small Animal Practice, v.36, p.667-85, 2006.

HOUGHTON, P.J. et al. In vitro tests and ethnopharmacological investigations: Wound healing as an example. Journal of Etnopharmacology, v.100, p.1007, 2005.

HSU, S. Green tea and the skin. Journal of American Academy of Dermatology, v.52, p.1049-59, 2005.

KRISHNAN, P. The scientific study of herbal wound healing therapies: current state of play. Current Anesthesia \& Critical Care, v.17, p.21-7, 2007. LAPA, A.J. et al. Métodos para avaliação da atividade farmacológica de plantas medicinais. Porto Alegre: Metrópole, 2003. 118p.

LOPES, G.C. et al. Influence of extracts of Stryphnodendron polyphyllum Mart. and Stryphnodendron obovatum Benth. on thecicatrisation of cutaneous wounds in rats. Journal of Ethnopharmacology, v.99, p.265-72, 2005.

LÓPEZ DE LEON, N.A.; ROJKIND, M. A simple micromethod for collagen and total protein determination in formalin-fixed paraffin-embedded sections. Journal of Hystochemistry and Cytochemistry, v.33, p.737-43, 1985.

LUNA, L.G. Manual of histologic staining methods of the armed forces Institute of Pathology. 3.ed. New York: McGraw-Hill, 1968. 258p.

MARTINS, P.S. et al. Comparação entre fitoterápicos de uso tópico na cicatrização de pele em eqüinos. Archives of Veterinary Science, v.8, n.2, p.1-7, 2003.

MIDWOOD, K.S.;WILLIAMS, L.V.; SCHWARZBAUER, J.E. Tissue repair and the dynamics of the extracellular matrix. The International Journal of Biochemistry \& Cell Biology, v.36, p.1031-7, 2004.

MONTENEGRO, J.F.; FRANCO, M. Patologia: processos gerais. 4.ed. São Paulo: Atheneu, 1999. 760p.

NATIONAL COMMITTEE FOR CLINICAL LABORATORY STANDARDS-NCCLS. In: Methods for diluition antimicrobial susceptibility tests for bacteria that grow aerobically. Villanova-PA: National Committee for Clinical Laboratory Standards, 2003. 520p. (Publication M6-T). OLIVEIRA, S.T. et al. Formulações do confrei (Symphytum officinalis L.) na cicatrização de feridas cutâneas em ratos. Revista da Faculdade de Zootecnia, Veterinária e Agronomia, v.7, n.1, p.61-5, 2000.

PACHALY, J.R. Terapêutica por extrapolação alométrica. In: CUBAS, Z.S.; SILVA, J.C.R.; CATÃO-DIAS, J.L. (Orgs.). Tratado de animais selvagens: medicina veterinária. São Paulo: Roca, 2006. 480p.

RASKIN, L. et al. Plants and human health in the twentyfirst century. TRENDS in Biotechnology, v.20, n.12, p.52231, 2002

SAMPAIO, I.B.M. Estatística aplicada à experimentação animal. Belo Horizonte: Fundação de Ensino e Pesquisa em Medicina Veterinária, 1998. 221p. 
STEERS, E.; FOLTZ, E.L.; GRAVES, V.S. An inocula replicating apparatus dor continue testing of bacterial susceptibility to antibiotics. Antibiotical and Chemotheraphy, v.9, p.307-11, 1959.

VOLPATO, A.M.M. Avaliação do potencial antibacteriano de Calendula officinalis (Asteraceae) para seu emprego como fitoterápico. 2005.133p. Tese (Doutorado em Ciências) - Setor de Química, Universidade Federal do Paraná, Paraná.

WORLD HEALT ORGANIZATION - WHO. Selected medicinal plants. Geneva: World Health Organization, 2002. v.2, 550p.

WHITE, G.W. Maltodextran, NF POWDER: a new concept in equine wound healing. Journal of Equine Veterinary Science, v.15, p.296-8, 1995.

ZITTERL-EGLSEER, K. et al. Anti-oedematous activities of the main triterpendiol esters of marigold (Calendula officinalis L.). Journal Ethnopharmacology, v.57, p.13944, 1997. 